\title{
PRODUKTIVITAS DAN BIAYA PRODUKSI SERPIH KAYU MENGGUNAKAN MESIN SERPIH MUDAH DIPINDAHKAN (SMD): Studi Kasus di BKPH Parungpanjang, Bogor
}

\section{(Productivity and Cost of Chip Production Using Portable Chipper : Case Study in BKPH Parungpanjang, Bogor)}

\author{
Oleh/By : \\ Achmad Supriadi, Osly Rachman \& M.I. Iskandar ${ }^{1)}$
}

\begin{abstract}
Forest harvesting activities generally produced a large quantity of woody wastes. Such materials could in fact be utilized for commercial and energy purposes.

This study examined the use of wood harvesting wastes for chip production using portable chipper. The study was accomplished in a planted forest at BKPH Parungpanjang, Bogor. Results indicated that average convertion factor of chip material was 1 staple meter $=0,4791 \mathrm{~m} 3=0,257$ ton. The yield of chip before and after screening were $97 \%$ dan $53 \%$, respectively. Productivity of chip was 1.6 ton/ day. Investation required to build 1 unitportable mill was approximately $\mathrm{Rp}$ 38.000.000. Annual production cost is about $\mathrm{R} p$ 173.075.84, while the chip production cost is approximately $\mathrm{Rp} 360.575$ per ton. Assuming chip price of $\mathrm{R} p 380.000$ per ton, the mill will obtain annual brutto income and net income of $\mathrm{R} p$ 8.944.000 and $\mathrm{R} p 7.602 .400$, respectively.
\end{abstract}

Keywords: Planted forest, wood waste, portable chipper, chip.

\begin{abstract}
ABSTRAK
Hasil pemanenan kayu di areal hutan baik hutan alam maupun hutan tanaman masih menyisakan potongan-potongan kayu kecil. Potongan kayu yang biasa disebut sebagai limbah pemanenan pada umumnya ditinggalkan di hutan dan sebagian yang dianggap masih laik dijual kepada penduduk sekitar hutan untuk dimanfaatkan sebagai kayu bakar atau bahan baku energi lainnya

Dalam rangka meningkatkan pemanfaatan limbah kayu dari hasil pemanenan hutan tanaman, telah dilakukan penelitian pengolahan limbah kayu jenis mangium (Accacia mangium) di areal hutan tanaman di BKPH Parungpanjang, Bogor. Hasil penelitian menunjukkan bahwa faktor konversi rartarata limbah pemanenan untuk bahan baku serpih (chip) adalah $1 \mathrm{sm}=0,4791 \mathrm{~m}^{3}=0,257$ ton. Rendemen serpih sebelum disaring dan setelah disaring masing-masing adalah $97 \%$ dan 53\%. Produktivitas penyerpihan adalah 1,6 ton/hari. Investasi pendirian satu unit pengolahan serpih kayu sebesar Rp 38.000.000. Biaya produksi per tahun sebesar Rp 156.109.113 dan harga pokok produksi
\end{abstract}

${ }^{1)}$ Peneliti pada Pusat Penelitian dan Pengembangan Hasil Hutan, Bogor 
serpih sebesar Rp 325.227 per ton serpih. Dengan harga jual serpih Rp 360.000 per ton, dapat diperoleh laba kotor dan laba bersih rata-rata per tahun masing-masing sebesar Rp 16.691.040 dan Rp 14.187.784.

Kata kunci : Hutan tanaman, limbah, mesin serpih mudah dipindahkan, serpih kayu

\section{PENDAHULUAN}

Hasil pemanenan kayu di areal hutan baik hutan alam maupun hutan tanaman masih menyisakan limbah kayu. Limbah kayu pada umumnya ditinggalkan di hutan dan sebagian yang masih laik dijual kepada penduduk sekitar hutan untuk dimanfaatkan sebagai kayu bakar atau bahan baku energi lainnya. Dulsalam et al. (2000) menyatakan bahwa limbah yang terjadi dari pohon yang ditebang yaitu berupa kayu sampai dengan diameter $15 \mathrm{~cm}$ adalah sebesar $57 \%$. Dengan demikian dolok yang dapat dimanfaatkan dari pohon yang ditebang tersebut sebesar 43\%. Jumlah limbah akan lebih besar lagi bila ditambah dari tegakan yang roboh tertimpa pohon yang ditebang.

Dengan perkembangan teknologi yang ada, sesungguhnya limbah tersebut dapat diolah menjadi produk serpih kayu (chip) yaitu dengan menggunakan mesin chipper. Agar lebih efisien, pengolahan limbah kayu menjadi serpih kayu sebaiknya menggunakan mesin serpih mudah dipindahkan. Kegiatan pembuatan serpih kayu akan meningkatkan nilai tambah, efisiensi pengolahan kayu, lapangan kerja dan pendapatan masyarakat. Produk serpih kayu dengan mesin serpih mudah dipindahkan dapat digunakan sebagai bahan baku pulp dan atau pabrik papan partikel. Disamping itu, produk serpih yang dihasilkan dapat diekspor untuk memenuhi pasar dunia terutama Jepang.

Laban (2003) melaporkan bahwa saat ini tercatat 6 buah pabrik pulp dengan kapasitas ijin 3,98 juta $\mathrm{m}^{3} /$ tahun dengan kebutuhan bahan baku 17,91 juta $\mathrm{m}^{3} /$ tahun. Harapan ini tidak tercapai, fakta yang ada menunjukkan bahwa selama periode tahun 2000-2002, produksi kayu dari hutan tanaman (HPHTI dan PT. Perhutani) hanya mencapai 3,87 juta $\mathrm{m}^{3} /$ tahun. Dalam keadaan demikian, maka kesulitan dalam penyediaan bahan baku pulp dan kertas dapat dipenuhi dari limbah eksploitasi.

Dalam penelitian ini dilakukan studi kelayakan pemanfaatan limbah eksploitasi kayu mangium untuk pembuatan serpih, dengan menggunakan mesin serpih mudah dipindahkan. Tujuan studi ini adalah mengkaji aspek ekonomis dari kegiatan produksi serpih.

\section{METODE PENELITIAN}

\section{A. Lokasi Penelitian}

Penelitian dilakukan di areal Perum Perhutani Unit III Jawa Barat, BKPH Parungpanjang, Bogor.

\section{B. Bahan dan Alat Penelitian}

Bahan yang digunakan dalam penelitian ini adalah bahan baku kayu berupa limbah pembalakan yang diperoleh dari hutan tanaman mangium di Jawa Barat, limbah ini berupa cabang, kayu yang tidak diangkut karena cacat,pecah, ujung pohon yang berdiameter kurang dari $15 \mathrm{~cm}$. 
Peralatan yang digunakan adalah mesin serpih mudah dipindahkan, gergaji rantai, gergaji tangan, golok, palu dan lain-lain. Untuk memproduksi serpih kayu dari limbah pemanenan kayu mangium digunakan mesin serpih mudah dipindahkan type 600 dengan spesifikasi sebagai berikut:

$\begin{array}{ll}\text { Kecepatan putaran mesin } & : 1.467 \mathrm{rpm} \\ \text { Diameter piringan (disk) } & : 50 \mathrm{~cm} \\ \text { Panjang pisau } & : 16 \mathrm{~cm} \\ \text { Lebar pisau } & : 13 \mathrm{~cm} \\ \text { Tebal pisau } & : 1,6 \mathrm{~cm} \\ \text { Sudut kemiringan pisau } & : 34 \text { derajat } \\ \text { Diameter lubang umpan } & : 40 \mathrm{~cm} \\ \text { Diameter lubang output } & : 45 \mathrm{~cm} \\ \text { Mesin penggerak diesel } & : \text { Yanmar }(13,5 \mathrm{PK}) \\ \text { Roda belakang } & : \mathrm{R} 13 \\ \text { Roda depan } & : \mathrm{R} 13 \\ \text { Panjang rangka } & : 300 \mathrm{~cm} \\ \text { Lebar rangka } & : 80 \mathrm{~cm} \\ \text { Tinggi rangka } & : 250 \mathrm{~cm}\end{array}$

Mesin serpih mudah dipindahkan dan mesin penggerak Yanmar ditempatkan dalam suatu rangka besi baja beroda empat. Profil mesin serpih mudah dipindahkan disajikan pada Gambar 1. Mesin ini memiliki kemampuan menyerpih kayu berdiameter $4-10 \mathrm{~cm}$ dan panjang 0,5 - $1 \mathrm{~m}$. Bila melebihi diameter tersebut, kayu dibelah terlebih dahulu.

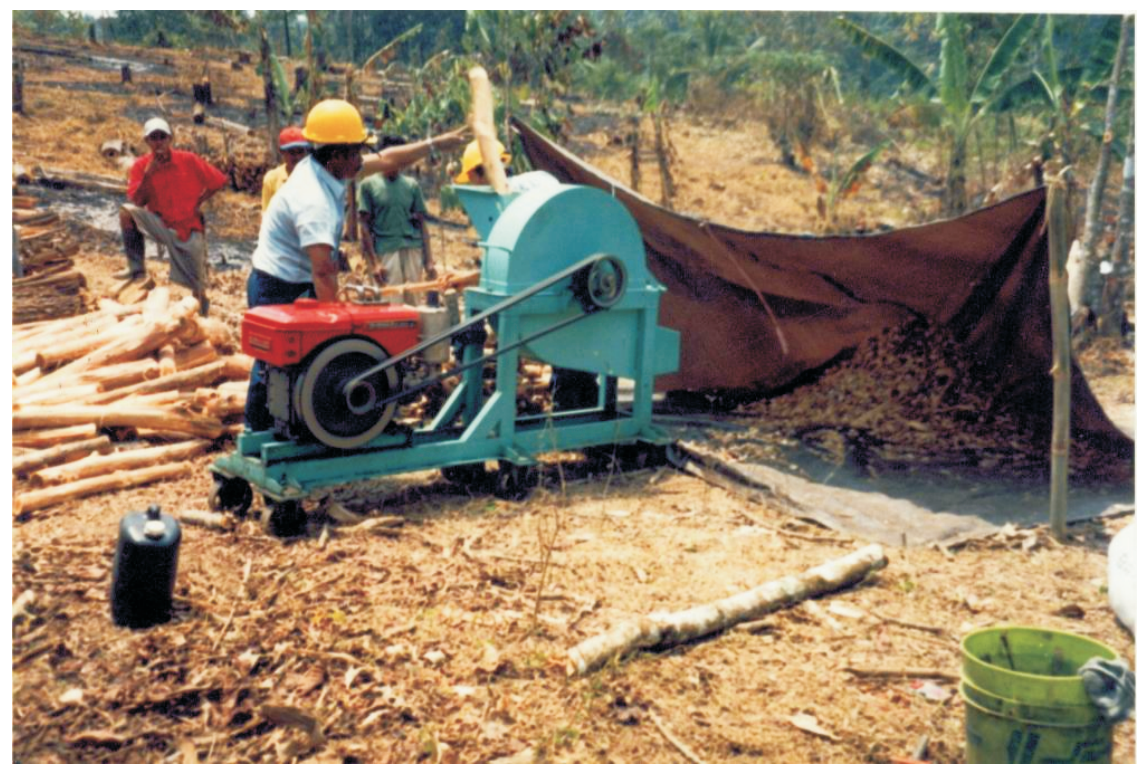

Gambar 1. Mesin serpih mudah dipindahkan type $\mathbf{6 0 0}$ Figure 1. Portable chipper machine type 600 


\section{Prosedur Kerja}

Proses pembuatan serpih kayu dimulai dengan cara menguliti bahan baku kayu secara manual. Kemudian dilakukan pengukuran berat kayu yang telah dikuliti. Kayu dipotong sesuai ukuran, lalu dimasukan ke mesin serpih mudah dipindahkan. Serpih kayu yang dihasilkan kemudian diayak (screening) dan dipisah-pisah menurut kelas mutu.

Data yang dikumpulkan meliputi data primer dan data sekunder. Data primer diperoleh melalui pengamatan dan pengukuran langsung sebagai berikut:

1. Pengukuran volume kayu

Volume kayu yang akan diserpih diukur menurut tumpukan (staple meter/sm). Terdapat 3 ukuran tumpukan yaitu ukuran $1 \mathrm{~m}$ (panjang) x $1 \mathrm{~m}$ (lebar) x $1 \mathrm{~m}$ (tinggi) dan $1 \mathrm{~m}$ (panjang) x 1,2 m (lebar) x $1 \mathrm{~m}$ (tinggi) serta $1 \mathrm{~m}$ (panjang) x $2 \mathrm{~m}$ (lebar) x $1 \mathrm{~m}$ (tinggi). Hasil pengukuran dinyatakan dalam satuan $\mathrm{m}^{3}$.

2. Pengukuran berat

Selain pengukuran volume, pada setiap tumpukan kayu yang akan diserpih tersebut juga diukur beratnya, menggunakan timbangan gantung. Setelah limbah kayu diserpih, kayu serpih ditimbang kembali dengan alat timbangan yang sama. Hasil pengukuran dinyatakan dalam satuan ton. Data hasil pengukuran berat digunakan untuk menghitung rendemen serpih.

3. Pengukuran produktivitas mesin

Pengukuran produktivitas mesin meliputi waktu penyerpihan dan volume serpih. Waktu penyerpihan diukur mulai kayu masuk ke mesin chipper sampai keluar berupa serpih kayu. Hasil pengukuran dinyatakan dalam satuan $\mathrm{m}^{3} / \mathrm{jam}$.

4. Pengukuran biaya produksi

Biaya produksi meliputi biaya langsung dan biaya tidak langsung. Biaya langsung terdiri dari bahan baku limbah kayu, bahan pembantu, gaji dan upah dan biaya pindah mesin. Sedangkan biaya tidak langsung terdiri dari biaya pemeliharaan alat dan bangunan, biaya penyusutan alat dan bangunan, asuransi, pajak dan bunga bank .

Data sekunder sebagai data pendukung diperoleh dari PT. Perhutani, Perusahaan pengolah serpih kayu dan telusuran pustaka.

\section{Pengolahan Data}

Dalam pengolahan data dihitung volume kayu yang diserpih, rendemen serpih, produktivitas pengolahan dan biaya pengolahan, dengan rumus sebagai berikut:

1. Volume kayu yang diserpih

$$
\mathrm{V}=1 / 4\left(\frac{\mathrm{D}+\mathrm{d}}{2}\right) 2 \times \mathrm{L}
$$

di mana: $\mathrm{V}=$ volume kayu $\left(\mathrm{m}^{3}\right)$

$\mathrm{D}=$ diameter pangkal $(\mathrm{m})$

$\mathrm{d}=$ diameter ujung $(\mathrm{m})$

$\mathrm{L}=$ panjang $(\mathrm{m})$

$\pi=3,14$ 
2. Rendemen serpih

$$
\begin{aligned}
\text { di mana: } & \mathrm{R}=\mathrm{Bs} / \mathrm{Blk} \times 100 \% \\
\mathrm{R} & =\text { Rendemen }(\%) \\
\mathrm{Bs} & =\text { Berat serpih (ton) } \\
\mathrm{Blk} & =\text { Berat limbah kayu (ton) }
\end{aligned}
$$

3. Produktivitas dihitung dengan rumus :

$$
\begin{aligned}
\text { di mana: } & \mathrm{P}=\frac{\mathrm{V} \times \mathrm{W}}{60} \\
\mathrm{P} & =\text { produktivitas }\left(\mathrm{m}^{3} / \mathrm{jam}\right) \\
\mathrm{W} & =\text { waktu yang diperlukan (menit) } \\
\mathrm{V} & =\text { volume serpih }\left(\mathrm{m}^{3}\right) ; \\
60 & =\text { konversi dari menit ke jam }
\end{aligned}
$$

4. Biaya produksi serpih

Biaya produksi serpih dihitung dengan rumus (Supriyono, 1995 dan FAO, 1974 dalam Dulsalam, 1996) sebagai berikut:

a. Biaya bahan baku $=$ harga limbah dari Perhutani + biaya eksploitasi + pajak $(10 \%$ dari harga pokok) $\mathrm{x}$ volume

b. Biaya bahan pembantu $=$ volume yang digunakan $\mathrm{x}$ harga per satuan

c. Gaji = jumlah orang $\mathrm{x}$ standar gaji per bulan

d. Upah $=$ volume output $\mathrm{x}$ standar upah per satuan

e. Biaya penyusutan alat $=\frac{\text { Harga alat }(\mathrm{Rp}) \times 0,9}{\text { Umur pakai alat (jam) }}$

f. Biaya perawatan dan perbaikan alat $=\frac{\text { Harga alat }(\mathrm{Rp}) \times 0,10}{1.000 \mathrm{jam}}$

g. Asuransi, pajak dan bank untuk alat $=\frac{\text { Harga alat (Rp) x 0,06 }}{1.000 \mathrm{jam}}$

h. Biaya penyusutan alat $=\frac{\text { Harga alat }(\mathrm{Rp}) \times 0,9}{\text { Umur pakai alat }(\text { jam })}$

i. Biaya perawatan dan perbaikan alat $=\frac{\text { Harga alat }(\mathrm{Rp}) \times 0,10}{1.000 \mathrm{jam}}$

j. Asuransi, pajak dan bank untuk bangunan $=$ Harga bangunan $(\mathrm{Rp}) \times 0,06$ $1.000 \mathrm{jam}$ 


\section{HASIL DAN PEMBAHASAN}

\section{A. Volume dan Berat Kayu}

Hasil pengukuran volume limbah pemanenan kayu mangium yang digunakan untuk bahan baku serpih pada setiap tumpukan disajikan pada Tabel 1.

Tabel 1. Volume limbah pemanenan kayu mangium untuk bahan baku serpih kayu Table 1. Mangium wood harvested volume for chip material

\begin{tabular}{|c|c|c|c|}
\hline No. & $\begin{array}{l}\text { Ukuran tumpukan } \\
\text { (Group size) }\end{array}$ & $\begin{array}{c}\text { Ulangan } \\
\text { (Replication) }\end{array}$ & Volume $\left(\mathrm{m}^{3}\right) / \mathrm{sm}$ \\
\hline 1. & $\begin{array}{l}1 \mathrm{sm} \\
1 \mathrm{~m}(\mathrm{p}) \times 1 \mathrm{~m}(\mathrm{l}) \times 1 \mathrm{~m}(\mathrm{t})\end{array}$ & 3 & 0.5334 \\
\hline 2. & $\begin{array}{l}1,2 \mathrm{sm} \\
1 \mathrm{~m}(\mathrm{p}) \times 1,2 \mathrm{~m}(\mathrm{l}) \times 1 \mathrm{~m}(\mathrm{t})\end{array}$ & 2 & 0.4696 \\
\hline 3. & $\begin{array}{l}2 \mathrm{sm} \\
1 \mathrm{~m}(\mathrm{p}) \times 2 \mathrm{~m}(\mathrm{l}) \times 1 \mathrm{~m}(\mathrm{t})\end{array}$ & 2 & 0.4344 \\
\hline & \multicolumn{2}{|c|}{ Rata-rata (Average) per sm } & 0,4680 \\
\hline
\end{tabular}

Keterangan $($ Remarks) $: \mathrm{sm}=$ staple meter; $\mathrm{p}=$ panjang $($ length $) ; \mathrm{l}=$ lebar (width); $\mathrm{t}=$ tebal (thick)

Pada Tabel 1 tampak bahwa rata-rata volume kayu/sm tertinggi pada tumpukan yang berukuran $1 \mathrm{sm}$ yaitu sebesar $0,5334 \mathrm{~m}^{3}$, kemudian menurun berturut-turut pada tumpukan $1,2 \mathrm{sm}$ dan $2 \mathrm{sm}$ masing-masing sebesar $0,4696 \mathrm{~m}^{3}$ dan $0,4344 \mathrm{~m}^{3}$. Dengan demikian, rata-rata volume per stapel meter limbah pemanenan kayu mangium yang digunakan dalam penelitian ini adalah $0,4680 \mathrm{~m}^{3}$. Terjadi kecenderungan makin besar ukuran tumpukan kayu, makin kecil rata-rata volume per stapel meternya dan sebaliknya. Hal ini diduga makin besar ukuran tumpukan kayu, makin besar kemungkinan terjadinya ruang-ruang kosong antara tumpukan kayu yang mengakibatkan makin sedikitnya jumlah kayu pada ukuran tumpukan yang makin besar, sehingga volumenya menjadi turun.

\section{B. Berat dan Rendemen}

Hasil pengukuran berat limbah kayu, berat serpih dan penghitungan rendemen masingmasing tumpukan disajikan pada Tabel 2. 
Tabel 2. Berat dan rendemen serpih kayu limbah pemanenan kayu mangium Table 2. Weight and recovery of chip of mangium wood waste barvest

\begin{tabular}{|c|l|c|c|c|c|}
\hline No & \multicolumn{1}{|c|}{$\begin{array}{c}\text { Ukuran tumpukan } \\
\text { (Group size) }\end{array}$} & $\begin{array}{c}\text { Ulangan } \\
\text { (Repl.) }\end{array}$ & $\begin{array}{c}\text { Berat limbah } \\
\text { kayu } \\
\text { Weight of wood } \\
\text { waste),ton/sm }\end{array}$ & $\begin{array}{c}\text { Rendemen } \\
\text { sebelum saring } \\
\text { Recovery } \\
\text { unscreen) } \\
(\%)\end{array}$ & $\begin{array}{c}\text { Rendemen } \\
\text { setelah saring } \\
\text { (Recovery } \\
\text { screened) } \\
(\%)\end{array}$ \\
\hline 1. & $\begin{array}{l}1 \mathrm{sm} \\
1 \mathrm{~m}(\mathrm{p}) \times 1 \mathrm{~m}(\mathrm{l}) \times 1 \mathrm{~m}(\mathrm{t})\end{array}$ & 3 & 0,2990 & 96,88 & 47,58 \\
\hline 2. & $\begin{array}{l}1,2 \mathrm{sm} \\
1 \mathrm{~m}(\mathrm{p}) \times 1,2 \mathrm{~m}(\mathrm{l}) \times 1 \mathrm{~m} \\
(\mathrm{t})\end{array}$ & 2 & 0,2621 & 96,65 & 56,58 \\
\hline 3. & $\begin{array}{l}2 \mathrm{sm} \\
1 \mathrm{~m}(\mathrm{p}) \times 2 \mathrm{~m}(\mathrm{l}) \times 1 \mathrm{~m}(\mathrm{t})\end{array}$ & 2 & 0,2090 & 96,93 & 56,29 \\
\hline \multicolumn{2}{|c|}{ Rata-rata (Average) per sm } & 0,2567 & 96,82 & 53,48 \\
\hline
\end{tabular}

Keterangan $($ Remarks) $: \mathrm{sm}=$ staple meter; $\mathrm{p}=$ panjang $($ length $) ; \mathrm{l}=$ lebar $($ width $) ; \mathrm{t}=$ tebal $($ thick)

Pada Tabel 2 tampak bahwa berat limbah kayu/sm (intake) tertinggi pada tumpukan yang berukuran $1 \mathrm{sm}$ yaitu sebesar 0,2990 ton, kemudian menurun berturut-turut pada tumpukan 1,2 sm dan $2 \mathrm{sm}$ masing-masing sebesar 0,2621 ton/sm dan 0,4344 ton/sm. Dengan demikian, rata-rata berat per stapel meter limbah pemanenan kayu mangium yang digunakan dalam penelitian ini adalah 0,2567 ton/sm. Terjadi kecenderungan makin besar ukuran tumpukan kayu, makin kecil rata-rata berat per stapel meternya dan sebaliknya. Hal ini berkaitan dengan kecenderungan makin kecilnya volume kayu pada ukuran tumpukan kayu yang lebih besar, seperti telah dijelaskan di atas.

Hasil perhitungan rendemen berdasarkan berat serpih baik sebelum dilakukan penyaringan mapun setelah disaring, diperoleh rata-rata rendemen serpih sebelum penyaringan sebesar $96,82 \%$. Sedangkan rendemen serpih setelah penyaringan adalah sebesar $53,48 \%$. Serpih kayu sebelum dilakukan penyaringan disajikan pada Gambar 2. 


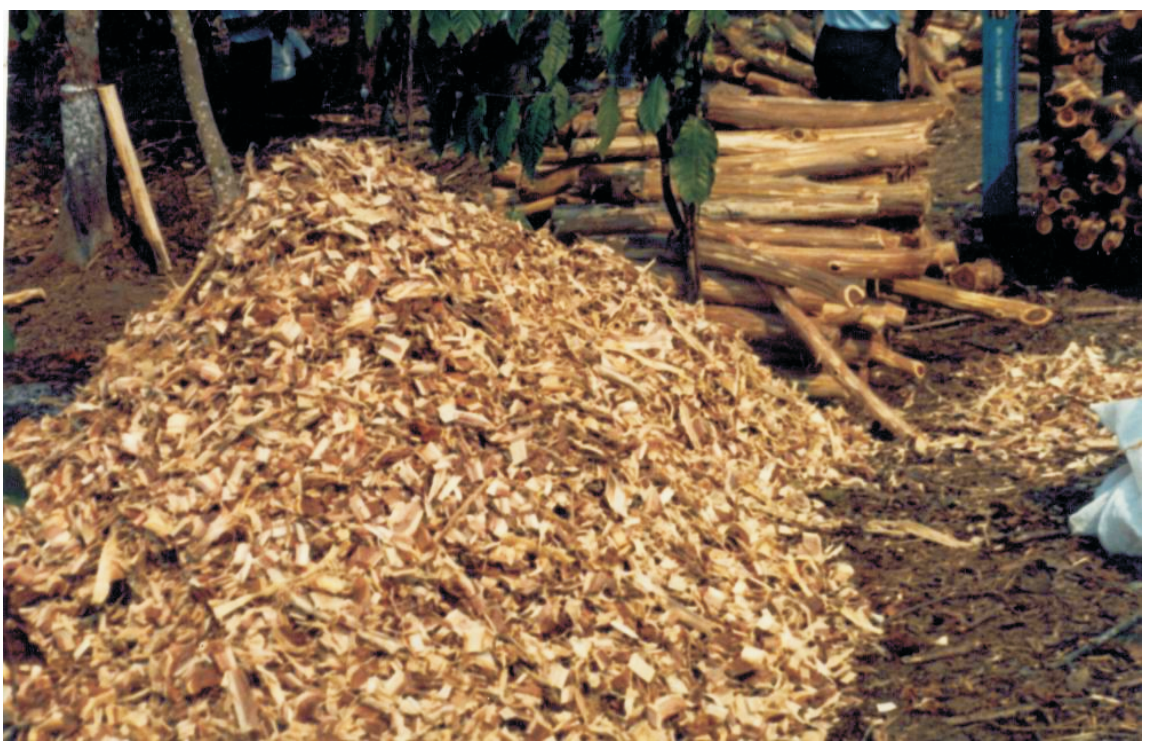

Gambar 2. Serpih kayu sebelum dilakukan penyaringan Figure 2. Chip wood before screening

\section{Produktivitas}

Hasil pengukuran produktivitas produksi serpih dari limbah pemanenan kayu mangium dari 1 unit mesin serpih mudah dipindahkan type 600 disajikan pada Tabel 3.

Tabel 3. Produktivitas pengolahan serpih dari limbah pemanenan kayu mangium Table 3. Productivity of chip production of mangium wood waste harvest

\begin{tabular}{|c|c|c|c|c|c|c|}
\hline \multirow{2}{*}{ No. } & \multirow{2}{*}{$\begin{array}{l}\text { Ukuran tumpukan } \\
\text { (Group size) }\end{array}$} & \multirow{2}{*}{$\begin{array}{l}\text { Ulangan } \\
\text { (Repl.) }\end{array}$} & \multirow{2}{*}{$\begin{array}{c}\text { Berat serpih } \\
(\text { chip weight }), \\
\text { ton } / \mathrm{sm}\end{array}$} & \multirow{2}{*}{$\begin{array}{l}\text { Waktu serpih } \\
\text { (Chip time), } \\
\text { menit }\end{array}$} & \multicolumn{2}{|c|}{$\begin{array}{l}\text { Produktivitas } \\
\text { (Productivity) }\end{array}$} \\
\hline & & & & & $\begin{array}{l}\text { Ton/ } \\
\text { hari }\end{array}$ & $\begin{array}{l}\text { Ton/ } \\
\text { tahun }\end{array}$ \\
\hline 1 & $\begin{array}{l}1 \mathrm{sm} \\
1 \mathrm{~m}(\mathrm{p}) \times 1 \mathrm{~m}(\mathrm{l}) \times 1 \mathrm{~m}(\mathrm{t})\end{array}$ & 3 & 0,142 & 38,49 & 1,55 & 464,85 \\
\hline 2 & $\begin{array}{l}1,2 \mathrm{sm} \\
1 \mathrm{~m}(\mathrm{p}) \times 1,2 \mathrm{~m}(\mathrm{l}) \times 1 \mathrm{~m}(\mathrm{t})\end{array}$ & 2 & 0,148 & 38,19 & 1,63 & 488,30 \\
\hline 3 & $\begin{array}{l}2 \mathrm{sm} \\
1 \mathrm{~m}(\mathrm{p}) \times 2 \mathrm{~m}(\mathrm{l}) \times 1 \mathrm{~m}(\mathrm{t})\end{array}$ & 2 & 0,118 & 30,28 & 1,63 & 488,30 \\
\hline \multicolumn{3}{|c|}{ Rata-rata (Average) per sm } & 0,136 & 35,65 & 1,61 & 480,48 \\
\hline
\end{tabular}

Keterangan $($ Remarks) : sm = staple meter; $\mathrm{p}=$ panjang $($ length $) ; \mathrm{l}=$ lebar (width); $\mathrm{t}=$ tebal (thick) 
Pada Tabel 3 tampak bahwa rata-rata berat serpih berkisar antara 0,118 ton/sm sampai 0,148 ton/sm dengan rata-rata 0,136 ton/sm, memerlukan rata-rata waktu serpih 35,65 menit. Dengan perhitungan 1 hari sama dengan 7 jam kerja efektif, mak produktivitas produksi serpih berkisar antara 1,55 ton/hari sampai 1,64 ton/hari, atau rata-rata 1,61 ton/hari. Dengan demikian dalam satu tahun (300 hari kerja) produktivitas produksi serpih kayu dari limbah pemanenan untuk 1 unit mesin serpih mudah dipindahkan mini type 600 berkisar antara 464 ton 488 ton atau rata-rata atau 480 ton/tahun.

\section{Investasi}

Investasi yang diperlukan untuk membangun satu unit pengolahan limbah kayu menjadi serpih kayu dengan menggunakan mesin serpih mudah dipindahkan adalah sebesar Rp 38.000.000 (Tabel 4). Investasi ini meliputi pengadaan mesin serpih mudah dipindahkan, mesin asah, pompa tangan, peralatan kantor dan bangunan semi permanen.

\section{Tabel 4. Rincian investasi pembangunan unit pengolahan serpih kayu} Table 4. Investment for building one unit chipping mill

\begin{tabular}{|c|l|r|}
\hline No. & \multicolumn{1}{|c|}{ Uraian (Description) } & Biaya (Cost), Rp \\
\hline 1. & Mesin penyerpih bergerak, buatan Taiwan (Portable chipper, & \\
& made in Taiwan) & 12.000 .000 \\
2. & Mesin asah, buatan Taiwan(Sharpener, made in Taiwan) & 4.000 .000 \\
3. & Gergaji rantai (Chain saw) & 4.000 .000 \\
4. & Pompa tangan (Portable water pump) & 150.000 \\
5. & Generator (Electric generator) & 4.000 .000 \\
6. & Mesin tik (Typewriter) & 250.000 \\
7. & Mesin hitung (Calculator) & 100.000 \\
8. & Meja dan kursi (Desk and chair) & 500.000 \\
9. & Bangunan semi permanen (Semi permanent building), & 13.000 .000 \\
& 3 x 7 m & 38.000 .000 \\
\hline
\end{tabular}

\section{E. Biaya dan Harga Pokok Produksi Serpih}

Biaya produksi serpih meliputi biaya bahan baku kayu dan biaya tenaga kerja. Perhitungan biaya produksi sangat tergantung pada hasil penelitian aspek teknis dan harga/biaya satuan yang berlaku saat itu. Hasil penelitian aspek teknis yang berpengaruh terhadap perhitungan biaya produksi adalah :

a. Rendemen rata-rata pengolahan serpih kayu, yaitu 53,48\%

b. Konversi rata-rata per staple meter kayu limbah adalah 0,299 ton, atau 1 ton kayu limbah setara dengan 2,244 stapel meter

c. Pemakaian solar untuk mesin serpih mudah dipindahkan dan gergaji rantai adalah 5,3 liter per ton serpih 
d. Pemakaian solar untuk generator Yanmar 13,5 PK adalah 2 liter per hari kerja

e. Frekuensi kepindahan mesin dalam setahun adalah 21 kali

Informasi pemakaian bahan pembantu lainnya diperoleh dari PT Bekasi Teguh, yaitu meliputi :

a. Pemakaian oli mesin untuk mesin serpih mudah dipindahkan adalah 0,13 liter per ton serpih

b. Pemakaian gemuk adalah $0,5 \mathrm{~kg}$ per ton serpih

c. Pemakaian pisau mesin serpih mudah dipindahkan adalah 0,04 buah per ton serpih

d. Pemakaian batu asah gurinda adalah 0,013 buah per ton serpih

e. Kapasitas produksi per tahun adalah 480 ton serpih atau 1,6 ton/hari. Kapasitas terpasang 1,52 ton/jam.

Standar harga/biaya yang digunakan adalah yang berlaku tahun 2002, yaitu :

a. Harga limbah kayu termasuk total biaya eksploitasinya per staple meter adalah Rp 23.375

b. Solar per liter Rp 1.400

c. Oli mesin per liter Rp 15.000

d. Gemuk per kg Rp 15.000

e. Pisau mesin serpih mudah dipindahkan per buah adalah Rp 300.000

f. Batu asah gurinda per buah Rp 250.000

g. Upah borongan pengolahan serpih/ $\mathrm{kg}$ Rp 60

h. Gaji pimpinan unit per bulan Rp 1.500 .000

i. Gaji operator mesin per bulan Rp 600.000

j. Biaya pindah mesin Rp 100.000 per $1 \times$ pindah

Dengan mengacu pada aspek teknis dan informasi biaya/harga, dihitung seluruh biaya yang terjadi, sehingga biaya produksi untuk menghasilkan 480 ton serpih adalah sebesar Rp 173.075.843,-. Rincian perhitungan harga pokok produksi serpih disajikan pada Tabel 5. 
Tabel 5. Harga pokok produksi serpih

Table 5. Cost of chip production

\begin{tabular}{|c|c|c|c|}
\hline No. & $\begin{array}{c}\text { Uraian } \\
\text { (Description) }\end{array}$ & $\begin{array}{c}\text { Biaya produksi } 480 \\
\text { ton serpih } \\
\text { (Production cost of } \\
480 \text { ton chip), } \\
\mathrm{Rp}\end{array}$ & $\begin{array}{l}\text { Biaya produksi } \\
\text { per ton serpih } \\
\text { (Production cost } \\
\text { per ton chip), } \\
\text { Rp }\end{array}$ \\
\hline \multirow{9}{*}{$\begin{array}{c}\text { A. } \\
1 . \\
2 .\end{array}$} & Biaya Langsung & & \\
\hline & Bahan baku limbah kayu & 70.130 .243 & 146.105 \\
\hline & Bahan pembantu : & & \\
\hline & $\begin{array}{l}\text { a. Solar untuk mesin serpih } \\
\text { mudah dipindahkan }\end{array}$ & 3.561 .600 & 7.420 \\
\hline & b. Solar untuk penerangan & 840.000 & 1.750 \\
\hline & c. Oli mesin & 936.000 & 1.950 \\
\hline & d. Gemuk & 3.600 .000 & 7.500 \\
\hline & $\begin{array}{l}\text { e. Pisau mesin serpih } \\
\text { mudah dipindahkan }\end{array}$ & 5.760 .000 & 12.000 \\
\hline & f. Batu asah gurinda & 1.560 .000 & 3.250 \\
\hline \multirow[t]{6}{*}{3.} & Gaji dan upah : & & \\
\hline & a. Borongan & 28.800 .000 & 60.000 \\
\hline & b. Pimpinan unit & 18.000 .000 & 37.500 \\
\hline & c. Operator mesin & 7.200 .000 & 15.000 \\
\hline & d. Staf & 7.200 .000 & 15.000 \\
\hline & e. Satpam & 7.200 .000 & 15.000 \\
\hline \multirow[t]{2}{*}{4.} & Biaya pindah mesin & 2.100 .000 & 4.375 \\
\hline & Jumlah biaya langsung : & 156.887 .843 & 326.850 \\
\hline \multirow[t]{9}{*}{ B. } & Biaya Tidak Langsung & & \\
\hline & Perawatan dan perbaikan alat & 5.250 .000 & $10.937,5$ \\
\hline & Perawatan dan perbaikan bangunan & 2.730 .000 & $5.687,5$ \\
\hline & Penyusutan alat & 2.250 .000 & $4.687,5$ \\
\hline & Penyusutan bangunan & 1.170 .000 & $2.437,5$ \\
\hline & Asuransi, pajak dan bank untuk alat & 3.150 .000 & $6.562,5$ \\
\hline & $\begin{array}{l}\text { Asuransi, pajak dan bank untuk } \\
\text { bangunan }\end{array}$ & 1.638 .000 & $3.412,5$ \\
\hline & Jumlah biaya tidak langsung & 16.188 .000 & 33.725 \\
\hline & Jumlah biaya produksi : & 173.075 .843 & 360.575 \\
\hline
\end{tabular}

\section{F. Proyeksi Pendapatan}

Proyeksi pendapatan dihitung dengan mengacu kepada harga jual serpih kayu. Harga jual serpih adalah berkisar antara Rp 360.000/ton (PT Bekasi Teguh) sampai Rp 400.000/ton (PT Tanjung Redeb Hutani) atau rata-rata Rp 380.000/ton.

Dengan asumsi harga jual serpih sebesar Rp 380.000/ton, maka dapat dihitung proyeksi pendapatan per tahun seperti disajikan pada Tabel 6. 
Tabel 6. Proyeksi pendapatan produksi serpih Table 6. Income projection of chip production

\begin{tabular}{|c|c|c|}
\hline $\begin{array}{c}\text { Tahun } \\
\text { (Year) }\end{array}$ & $\begin{array}{c}\text { Laba kotor } \\
\text { (Earning before tax), Rp }\end{array}$ & $\begin{array}{c}\text { Laba bersih } \\
\text { (Earning after tax), Rp }\end{array}$ \\
\hline 1 & -25.256 .000 & -21.467 .600 \\
2 & 12.744 .000 & 10.832 .400 \\
3 & 12.744 .000 & 10.832 .400 \\
4 & 12.744 .000 & 10.832 .400 \\
5 & 12.744 .000 & 10.832 .400 \\
6 & 12.744 .000 & 10.832 .400 \\
7 & 12.744 .000 & 10.832 .400 \\
8 & 12.744 .000 & 10.832 .400 \\
9 & 12.744 .000 & 10.832 .400 \\
10 & 12.744 .000 & 10.832 .400 \\
\hline Rata-rata & 8.944 .000 & 7.602 .400 \\
(Average) & & \\
\hline
\end{tabular}

Pada Tabel 6. tampak bahwa pada tahun pertama unit pengolahan masih menderita kerugian yaitu sebesar $\mathrm{Rp} 25.256 .000$. Hal ini disebabkan besarnya biaya investasi yang harus dikeluarkan pada tahun pertama yaitu sebesar Rp 38.000.000. Mulai tahun ke 2 dan seterusnya, unit pengolahan diperkirakan mampu memperoleh laba kotor per tahun sebesar Rp 12.744.000. Dengan tingkat pajak 15\%, akan diperoleh pendapatan bersih per tahun sebesar Rp 10.832.400. Rata-rata laba kotor per tahun sebesar Rp 8.944 .000 atau laba bersih per tahun Rp 7.602.400.

\section{KESIMPULAN}

1. Hasil penetapan faktor konversi rarta-rata limbah pemanenan kayu mangium dari hutan tanaman BKPH Parungpanjang Bogor untuk bahan baku serpih adalah $1 \mathrm{sm}=0,4791 \mathrm{~m}^{3}$ $=0,257$ ton, pada kisaran volume tumpukan $1-2 \mathrm{sm}$. Rendemen serpih setelah disaring adalah $53,48 \%$. Produktivitas penyerpihan adalah 1,6 ton/hari.

2. Investasi pendirian unit pengolahan serpih kayu sebesar Rp 38.000.000. Biaya produksi per tahun sebesar Rp 173.075.843 dan harga pokok produksi serpih sebesar Rp 360.575/ ton. Dengan harga jual serpih Rp 380.000 per ton, dapat diperoleh laba kotor dan laba bersih rata-rata per tahun masing-masing sebesar Rp 8.944.000 dan Rp 7.602.400.

3. Usaha unit pengolahan serpih kayu merupakan usaha yang besar manfaatnya dalam rangka meningkatkan nilai tambah dari limbah kayu. 


\section{DAFTAR PUSTAKA}

Dulsalam. 1996. Produktivitas dan biaya traktor pertanian untuk pengangkutan bibit dalam pembangunan hutan tanaman industri. Buletin Penelitian Hasil Hutan 14(10): 433-443. Pusat Penelitian dan Pengembangan Hasil Hutan dan Sosial Ekonomi Kehutanan. Bogor.

Dulsalam, D. Tinambunan, I. Sumantri dan M. Sinaga. 2000. Peningkatan efisiensi Pemungutan Kayu Sebagai Bahan baku Industri. Makalah Utama Lokakarya Penelitian Hasil Hutan. Pusat Penelitian Hasil Hutan tanggal 7 Desember 2000 di Bogor. Tidak diterbitkan.

Laban, B.Y. 2003. Kebijakan Restrukturisasi Industri Kehutanan Berbasis Pengolahan Hutan Lestari. Makalah Utama pada Ekspose Hasil-Hasil Litbang Hasil Hutan tanggal 16 Desember 2003. Pusat Litbang Teknologi Hasil Hutan. Bogor.

Supriyono, R. 1995. Akuntansi Manajemen. Badan Penerbit Fakultas Ekonomi. Yogyakarta. 